\title{
Los trabajadores ferroviarios ante los accidentes de trabajo. Denuncias, reclamos y demandas en la Argentina de comienzos del siglo XX
}

\author{
FLORENCIA D’UVA
}

Consejo Nacional de Investigaciones Científicas y Técnicas. Instituto de Investigaciones en Estudios de Género, Universidad de Buenos Aires

florenciaduva87@gmail.com

\begin{abstract}
Resumen: A partir de un corpus documental que incluye prensa sindical, política y nacional, fallos judiciales e informes publicados por el Departamento Nacional del Trabajo, este artículo analiza los accidentes de trabajo en los ferrocarriles de la Argentina durante las primeras dos décadas del siglo XX. Al poner el foco en las denuncias, reclamos y demandas formuladas por los trabajadores, sus familiares, y sus organizaciones gremiales, busca conocer las formas en que los ferroviarios vivieron los peligros y responsabilidades a las que estaban expuestos y cuáles fueron algunas de las acciones emprendidas para reclamar por lo que consideraban justo. Se espera con ello recuperar el rol que los propios trabajadores desempeñaron en la conquista de mejores condiciones laborales, derechos y leyes obreras.
\end{abstract}

Palabras clave: ferrocarriles, accidentes, trabajadores, demandas, Argentina

Recibido: 15 de enero de 2021. Aprobado: 23 de marzo de 2021. 


\section{Introducción}

El 2 de abril de 1914, a las cuatro de la mañana, desde la estación central de Retiro, en la ciudad de Buenos Aires, había salido con dirección a Tigre un tren compuesto de tres coches y arrastrado por la locomotora número 1016 del Ferrocarril Central Argentino, manejada por el maquinista Carlos Camp y el foguista Carlos Colombo. A la altura del Golf, la estación anterior a Belgrano, el tren comenzó a dar pequeños saltos sobre los rieles, lo que llamó la atención del conductor quien decidió disminuir la velocidad. Camp llevaba más de una década de servicio como maquinista y seguramente la experiencia le había enseñado qué hacer frente a un imprevisto como este. ${ }^{1}$ Pero enseguida hubo un golpe más violento y la locomotora saltó de la vía. Al darse cuenta de lo sucedido, y para detener la marcha del tren, Camp abrió las válvulas de escape “con todas sus fuerzas". Después de correr varios metros fuera de los rieles, la máquina volcó, arrastrando en su caída al primer coche y haciendo chocar a los demás entre sí de manera violenta. Mientras el pánico se apoderaba de muchos pasajeros que corrían ante el temor de que explotara la caldera, otros se encontraban heridos en los vagones y apenas podían lanzar algún quejido. El maquinista Camp, a duras penas, logró salir de la locomotora. Tenía las manos y la cara quemadas por el vapor, al haberle dado salida para detener el tren. Su compañero, el foguista Colombo, no tuvo la misma suerte. Mutilado, yacía bajo los restos de la locomotora que en su caída lo había arrastrado. ${ }^{2}$

La trágica muerte de Colombo conmocionó a sus compañeros de trabajo y de La Fraternidad, el gremio de maquinistas y foguistas. En una extensa crónica, el periódico sindical dio cuenta de lo ocurrido y, con un tono de indignación seguramente relacionado con la sensación de injusticia que los accidentes despertaban entre los trabajadores del riel, realizó algunas reflexiones acerca de los riesgos de la profesión y la indiferencia que empresas y público en general mostraban ante estos sucesos:

En su puesto de trabajo, de responsabilidad y de peligro, jamás el personal se ve considerado de acuerdo con su delicada tarea; el público no se preocupa nunca de aquellos que llevan en las manos, sus vidas e intereses; las empresas, apenas si se acuerdan de su personal, más que para presionarlo y deprimirlo.

Es necesario que una catástrofe se produzca, para que recién entonces, obligada la curiosidad pública, se magnifique la profesión, reconociéndose su peligro y responsabilidad.

1 Cédula de ingreso núm. 2318, Cédulas de ingreso a La Fraternidad, Tomo 2129-2500.

2 "El grave accidente del Golf (FCCA)", La Fraternidad (en adelante $L F$ ) 15 de abril de 1914, 1. 
Recién entonces, puede apreciarse hasta qué punto es de delicado y expuesto el trabajo de esos dos hombres, que en la plataforma de la locomotora, accionan sin descanso para manejar a su antojo el monstruo de hierro, que arrastra a través de los campos, de las montañas y de los ríos, miles de vidas y cuantiosos intereses. ${ }^{3}$

Pasado el tiempo, agregaba la crónica, la atención general y el recuerdo de la catástrofe iban desapareciendo y todo volvía a la normalidad, hasta que ocurriera un nuevo siniestro. A partir del fragmento citado es posible acercarse al imaginario que ciertos trabajadores ferroviarios construían sobre su profesión, al presentarse como una especie de héroes anónimos entregados al trabajo, poseedores de saberes especiales que no eran valorados, héroes que, deshumanizados por empresas y público, buscaban ser reconocidos.

Este tipo de noticias, en las que se informaba sobre un accidente poniendo de relieve los peligros poco reconocidos de la profesión, fueron frecuentes en las páginas de los periódicos de los gremios ferroviarios durante las primeras décadas del siglo XX. En general, se aprovechaba la ocasión para denunciar las malas condiciones de trabajo y la falta de mantenimiento de las vías y el material rodante por parte de las empresas, que exponían a sus trabajadores y pasajeros a riesgos mortales. Frente a esta situación, los trabajadores ferroviarios, sus familiares y sus organizaciones gremiales expresaron sus demandas en distintos ámbitos. En las páginas de los periódicos sindicales advirtieron sobre los riesgos de su profesión y denunciaron a las empresas, las cuales, según se afirmaba, en su afán por reducir los costos y maximizar sus ganancias, cometían todo tipo de irregularidades poniendo en peligro a sus trabajadores y pasajeros. También, reclamaron frente a jefes y superiores, exigiendo mejores condiciones de trabajo, y ante los poderes públicos, solicitando su intervención para regular lo que consideraban arbitrariedades e injusticias de las compañías. Otro recurso posible, aunque implicaba correr ciertos riesgos e invertir tiempo y dinero, era presentarse en la Justicia y exigir una indemnización que resarciera los daños y perjuicios ocasionados.

Diversos investigadores han indagado los accidentes de trabajo en la Argentina, poniendo el foco en la Ley 9.688 de Accidentes del Trabajo y Enfermedades Profesionales sancionada en 1915, principalmente en el papel que ciertos funcionarios estatales desempeñaron en su impulso, elaboración y sucesivas modificaciones. Si bien a mediados de la década de 1980 algunos estudios examinaron los antecedentes y debates previos a la aprobación de la ley, considerando fundamentalmente las posturas y acciones de distintos sectores y partidos políticos, funcionarios y representantes

3 "El grave accidente", $L F, 1$. 
gubernamentales, ${ }^{4}$ durante los últimos años el tema originó una creciente atención. Con preguntas renovadas e intereses diversos, algunas autoras y autores volvieron a abordar la sanción de la ley, los debates previos, los desafíos de su implementación y los cambios introducidos a lo largo del tiempo. Algunas de estas investigaciones analizaron el rol de los intelectuales y diversos agentes de la elite liberal en la elaboración de políticas tendientes a garantizar la salud y seguridad de los trabajadores entre fines del siglo XIX y principios del siguiente, y otras examinaron el accionar de los magistrados en las demandas judiciales por accidentes de trabajo durante los primeros años del siglo XX. ${ }^{5}$ Asimismo, entre las producciones más recientes, diversos escritos enfocaron su mirada en la perspectiva de médicos y juristas, analizaron la circulación de ideas internacionales sobre las nociones del riesgo profesional y reparaciones de accidentes de trabajo que atravesaron la discusión de la ley en Argentina, estudiaron las modificaciones e implementación de la ley desde su sanción hasta mediados del siglo XX y rastrearon las nociones y definiciones de trabajo asociadas a la ley. ${ }^{6}$

En el plano latinoamericano, la historiografía dedicada a analizar los accidentes de trabajo ocurridos durante las primeras décadas del siglo XX ha seguido una tendencia similar, con estudios mayoritariamente preocupados por reconstruir las discusiones, opiniones y medidas tomadas por médicos, abogados y gobernantes en el marco de la creciente atención concitada por las consecuencias no deseadas de la industrialización. A lo largo de la última década fueron varias las investigaciones que examinaron los accidentes

4. Ernesto Isuani, Los orígenes conflictivos de la seguridad social argentina (Buenos Aires: CEAL, 1985); José Panettieri, Las primeras leyes obreras (Buenos Aires: CEAL, 1984).

5 Victoria Haidar, Trabajadores en riesgo. Una sociología histórica de la biopolítica de la población asalariada en Argentina (1890-1915) (Buenos Aires: Prometeo, 2008); Pablo Maddalena, "Reflexiones sobre el estudio de las políticas de protección social en la Argentina de la primera mitad del siglo XX”, Estudios Sociales del Estado, 1 (2015): 121-138; María Belén Portelli, "Saberes modernos para políticas eficaces. El derecho laboral y el estudio del mundo del trabajo. Córdoba, 1906-1930", Población y Sociedad, 18 (2011): 145-185; Line Schjolden, "Sentencing the Social Question: Court-Made Labour Law in Cases of Occupational Accidents in Argentina, 1900-1915", Journal of Latin American Studies, 41 (2009): 91-120.

6 Inés Pérez, "Una línea fluctuante: el servicio doméstico y el régimen de accidentes de trabajo (1915-1956)", Estudios Sociales, 49 (2015): 155-182; Karina Ramacciotti, "De la culpa al seguro. La Ley de Accidentes de Trabajo, Argentina (1915-1955)", Mundos do Trabalho, 3 (2011): 266-284; Karina Ramacciotti, "Influencias internacionales sobre la gestión de los accidentes de trabajo en Argentina. Primera mitad del siglo XX”, e-l@tina, 12 (2014):21-42; Andrés Stagnaro, "La Ley de Accidentes del Trabajo y los debates promovidos para la creación de un fuero laboral (Argentina, 1904-1946)”, Estudios Sociales, 50 (2016): 111-143. 
laborales en Colombia, Chile y Brasil, abordando los debates que antecedieron y sucedieron a la sanción de las legislaciones de 1915, 1916 y 1919 respectivamente, sus reformas posteriores, así como los discursos e interpretaciones médico-legales de los accidentes, sin prestar demasiada atención a los reclamos que emanaban desde el sector obrero. ${ }^{7}$ Algunas pesquisas, sin embargo, avanzaron en este sentido, interesadas por conocer las demandas de los trabajadores, sus esfuerzos por hacer cumplir la ley y el impacto que sus acciones tuvieron en algunas de las reformas introducidas a la legislación. ${ }^{8}$

En lugar de centrarse en las acciones y debates que tuvieron lugar entre funcionarios y agencias estatales, médicos, abogados, jueces, intelectuales y dirigentes políticos, este artículo busca recuperar la perspectiva de los propios trabajadores. Para ello, analiza los accidentes en los ferrocarriles de la Argentina durante las primeras dos décadas del siglo XX y, al considerar las denuncias, reclamos y demandas formuladas por los trabajadores y sus organizaciones, busca desentrañar las formas en las que vivieron sus experiencias laborales y los peligros a los que estaban expuestos. Se propone conocer algunos de los sentidos que los ferroviarios imprimieron a sus vidas y trabajos, cómo vivieron la injusticia, cuáles eran sus expectativas en relación a la problemática de los accidentes de trabajo y cómo a partir de ellas libraron luchas y contiendas en las que se gestaron demandas por derechos. Indaga las expectativas, nociones sobre lo justo y estrategias desplegadas por los propios trabajadores damnificados o sus familiares para conseguir una indemnización o resarcimiento, sobre todo en los años previos a la sanción de

7 Evangelina Aravanis, "Os processos de acidentes de trabalho na capital do Rio Grande do Sul no início da Era Vargas: embates entre a Justiça, o patronato e o trabalhador", Revista Latino-Americana de História, 1 (2012): 300-310; Eduardo L. Leite Ferraz, “Acidentados e remediados: a lei de acidentes no trabalho na Piracicaba da Primeira República (1919-1930)”, Mundos do Trabalho, 2 (2010): 206-235; Oscar Gallo, "Acidentes de trabalho na Colômbia. Doutrina, lei e jurisprudência (1915-1950)”, Mundos do Trabalho, 7 (2015): 129-149; Bruno Mandelli y João Henrique Zanelatto, “As fontes judiciais como material de pesquisa para a História Social e Política: os processos de acidentes de trabalho no contexto da legislação social”, Cadernos do Ceom, 32 (2019): 36-46; Diego Ortúzar, "Legislación y medicina en torno a los accidentes del trabajo en Chile 1900-1940”, Nuevo Mundo Mundos Nuevos (2013).

8 Evangelina Aravanis, "Um Olhar Sobre os Processos de Acidentes de Trabalho no Rio Grande do Sul (1934-1950)”, Aedos, 2 (2009): 89-94; Sergio Grez Toso, "El escarpado camino hacia la legislación social: debates, contradicciones y encrucijadas en el movimiento obrero y popular (Chile: 1901-1924)", Cyber Humanitatis, 41 (2007): 1-48; Bruno Mandelli, "Os processos de acidentes de trabalho dos mineiros na capital brasileira do carvão: a luta pelo direito à saúde”, Estudios Históricos, 18 (2017); Isabelle C. da Silva Pires, "Centenário da Lei de Acidentes de Trabalho: análise sobre acidentes em fábricas de tecidos do Rio de Janeiro na Primeira República”, Mundos do Trabalho, 11 (2019): 1-22. 
una ley, y se detiene en la recepción, cambios e inconvenientes que esta presentó en los primeros años de implementación.

Para lograr su objetivo, el artículo se vale de un corpus documental variado que incluye prensa gremial, política y nacional, documentación sindical, fallos judiciales e informes elaborados y publicados por el Departamento Nacional del Trabajo. La primera parte examina las denuncias y reclamos formulados por los trabajadores desde las páginas de los periódicos gremiales en los años previos a la existencia de una legislación. A continuación, el análisis se detiene en las demandas de los trabajadores accidentados y sus familiares ante la Justicia para conseguir una indemnización o resarcimiento, mientras que el último apartado estudia los cambios y continuidades que se produjeron a partir de 1915, año de la sanción de la ley de accidentes del trabajo.

\section{Denuncias y reclamos en la prensa gremial}

Los periódicos gremiales constituyen una fuente rica y compleja que permite, no sin limitaciones, reconstruir algunos de los objetivos, intereses y estrategias que los trabajadores ferroviarios organizados desarrollaron para luchar por mejores condiciones de vida y trabajo. Allí se publicaban denuncias, quejas y reclamos, tanto individuales como colectivos, que llegaban desde las distintas secciones que tanto La Fraternidad (LF) -gremio de maquinistas y foguistas-como la Federación Obrera Ferrocarrilera (FOF) -sindicato que agrupaba al personal de talleres, tráfico y vía y obras- tenían a lo largo y ancho del país. Considerando que el análisis de la prensa gremial puede aportar al conocimiento de la cultura obrera y la forma en que los trabajadores vivían sus experiencias laborales y condiciones de vida, ${ }^{9}$ a partir de la lectura de los periódicos de estos gremios se busca entrever cómo los propios trabajadores ferroviarios entendieron los accidentes, peligros y riesgos a los que estaban expuestos, y formularon denuncias y reclamos al respecto.

Desde su aparición, en 1907 y 1912, tanto La Fraternidad (LF) como El Obrero Ferroviario (EOF) publicaron noticias que informaban sobre accidentes ocurridos en servicio, trabajadores fallecidos o heridos en estos siniestros, y en las que se denunciaban injusticias, arbitrariedades e irregularidades de las empresas y los poderes públicos, subrayándose los peligros de la profesión ferroviaria. Las denuncias en los periódicos eran una construcción colectiva que requería de la colaboración de todos los asociados. A los pocos meses de su aparición, en febrero de 1908, el periódico de LF inauguró la sección "Lo que dice el personal", donde se publicaba la correspondencia que desde las distintas secciones se remitían a la redacción.

$9 \quad$ Mirta Z. Lobato, La prensa obrera (Buenos Aires: Edhasa, 2009), 20. 
Durante las primeras ediciones, este apartado iba acompañado de la leyenda "La publicación de las quejas es uno de los medios eficaces para su desaparición”. ${ }^{10}$ Por su parte, desde su lanzamiento en junio de 1912, EOF solicitó a sus afiliados su cooperación con la denuncia de las injusticias y atropellos cometidos contra los obreros ${ }^{11}$ y en el transcurso de unos pocos meses comenzó a publicar la sección "Las empresas y la organización” que reunía la información que llegaba desde las secciones a través de sus delegados o corresponsales.

Una de las quejas reiteradas a lo largo de los años fue aquella relativa al descuido y mal estado de muchas de las instalaciones como consecuencia de la "economía” de las empresas ferroviarias que, según acusaban numerosas notas, no realizaban un mantenimiento adecuado del material rodante y las vías ni tomaban las medidas de seguridad necesarias para prevenir accidentes. A fines de 1913, trabajadores del ferrocarril de capitales británicos Central Córdoba denunciaron que las autoridades de esta compañía ahorraban en el líquido con el que se encendían los faroles de las señales por la noche, lo que no solo iba en contra del Reglamento General de Ferrocarriles sino que exponía al público y al personal a sufrir accidentes, al circular los trenes sin señales encendidas en las vías. ${ }^{12}$ Un año más tarde, una nota publicada en el periódico de LF advirtió que era de lo más común que las empresas exoneraran al personal de máquinas que hubiera "caído en la trampa de la vía muerta de alguna estación”, culpándolo de haber descarrilado por "imprudencia”. ${ }^{13}$ Denunció que en estos casos era inútil demostrar que los descarrilamientos se debían a deficiencias o desperfectos del material, puntualmente de los cambios, cuyos mecanismos nadie controlaba, con la consecuencia de que los accidentes se sucedían sin interrupción y los maquinistas eran considerados culpables. ${ }^{14}$ A principios de 1914, EOF lo había expresado de manera contundente:

... a este infame sistema de reducción de personal, de aumento desmedido de las tareas, a ese plan descabellado que impropiamente se ha dado en llamar de economías, SON DEBIDOS LA MAYOR PARTE DE LOS

10 A fines de 1912 este periódico llamaba a los asociados a denunciar los abusos e injusticias cometidas por las empresas y sus superiores, recordando que hacía seis años que intentaba demostrar que la publicación de las arbitrariedades era el mejor remedio para su eliminación, ("Publicar el abuso", $L F, 15$ de noviembre de 1912, 2).

11 “A los colaboradores”, El Obrero Ferroviario (en adelante EOF), julio y agosto de 1912, 2.

12 "En el Ferrocarril C. Córdoba. Economía mal entendida", $L F, 15$ de octubre de 1913, 2.

13 "Las trampas de las vías y las de las Empresas", $L F, 15$ de diciembre de 1914, 2.

14 "Las trampas de las vías", $L F, 2$. 
ACCIDENTES, DESCARRILAMIENTOS y demás trastornos que cuestan cada año centenares de vidas. ${ }^{15}$

En efecto, no eran pocos los casos en que la falta de mantenimiento y la ausencia de medidas de seguridad desembocaban en accidentes mortales, como sucedió con Bernardo Fenaglio, trabajador de los talleres que el Ferrocarril Oeste tenía en la localidad de Mechita, provincia de Buenos Aires. El 25 de agosto de 1913, Bernardo pulía una planchuela con una máquina que no contaba con el seguro correspondiente, cuando la piedra se quebró y varios trozos impactaron en su pecho de manera violenta, provocando su muerte. Quien escribió la crónica del incidente para que fuera publicada en el periódico gremial remarcó que la responsabilidad de lo sucedido era enteramente de la empresa que días después del hecho, "como reconociendo su crimen”, había mandado a colocar un seguro. ${ }^{16}$ También el accidente que dejó sin vida al foguista Colombo, narrado al comienzo de este artículo, había tenido como causa la falta de mantenimiento. Según informó la crónica gremial, si bien en un comienzo se quiso adjudicar el descarrilamiento a un exceso de velocidad en la curva o a una frenada violenta, finalmente se había comprobado que la vía se encontraba "completamente floja en varios sitios", debido a unos trabajos recientes que se habían efectuado para su electrificación. De hecho, el maquinista que había pasado antes por el sitio había notado la flojedad de los rieles, avisando de inmediato a la superioridad que no alcanzó a tomar ninguna precaución. ${ }^{17}$

Varias noticias denunciaron la ausencia de medidas de seguridad necesarias para prevenir accidentes, inclusive cuando algunos trabajadores habían informado y advertido sobre posibles peligros. En el caso de los galpones de máquinas o depósitos de locomotoras, las empresas disponían de libros en donde el personal anotaba las reparaciones que consideraba oportunas pero, según se denunció en reiteradas oportunidades, los superiores solían desestimarlas o carecían de los elementos necesarios para efectuarlas. ${ }^{18}$ Por este motivo, a fines de 1908 un informe de un grupo de maquinistas de Huinca Renancó, empleados en la compañía de capitales británicos Ferrocarril Pacífico, advirtió que muchos de ellos corrían con máquinas defectuosas, expuestos a ser multados por exceso de consumo, atrasos en el horario y

15 “¡Como se hacen las economías!”, EOF, marzo de 1914, 1 (mayúscula en el original).

16 "Necrológica”, EOF, septiembre de 1913, p. 3.

17 "El grave accidente del Golf (FCCA)", $L F, 15$ de abril de 1914, 4.

18 "De Gálvez. FCR.”, $L F, 1$ de mayo de 1908, 7; "Del Ferrocarril Sud. Galpón de Tolosa”, $L F 1$ de agosto de 1908, 6; "Corral de Bustos. FCCA", LF, 1 de febrero de 1909, 7; "El gran siniestro del Argentino del Norte. La desidia crónica de la empresa. El accidente causa numerosas víctimas. Relatos de los sobrevivientes", $L F, 1$ de abril de 1911, 7; "FCP de Villa Mercedes", $L F, 1$ de diciembre de 1911, 10 . 
desperfectos en la máquina, y denunció que las reparaciones que el personal anotaba se hacían según el capricho de la superioridad. ${ }^{19}$ Unos meses más tarde, maquinistas del Central de Buenos Aires informaron que el personal siempre anotaba las reparaciones -para evitar que se les adjudicara la responsabilidad si ocurría algún accidente- pero que en el último tiempo se les había prohibido realizar anotaciones bajo pena de suspensión. Así, la empresa los obligaba a salir con máquinas en mal estado y se libraba de los compromisos legales, al evitar que existiera constancia de los peligros que estos advertían. ${ }^{20}$

Lo que se atacaba, en este y otros casos, era la falta de prevención y la desidia de las compañías, que esperaban que los accidentes sucedieran en lugar de intervenir a tiempo. También se apuntaba contra las autoridades nacionales, a quienes se acusaba de no controlar a las empresas, las cuales, según afirmaban los obreros agremiados, se manejaban a su antojo sin respetar las leyes y reglamentaciones vigentes. ${ }^{21}$ En este sentido, a comienzos de 1909, en el periódico de LF una nota firmada por "quilmeño", un asociado gremial, señaló que el estado descuidado de las máquinas era un mal que aquejaba a todas las empresas ferroviarias del país. Llamó la atención a las autoridades nacionales por no cumplir con el artículo $8^{\circ}$ de la Ley de Ferrocarriles, que establecía que la Dirección General haría reconocer periódicamente el material de explotación y haría excluir del servicio al que no ofreciese la seguridad necesaria. ${ }^{22}$ Según este trabajador, no existía ningún control sobre las empresas, las cuales hacían lo que se les antojaba, llevando la economía "hasta lo imposible" con el fin de obtener el máximo rendimiento de los materiales con el mínimo de reparaciones, exponiendo diariamente a su público y personal. ${ }^{23}$ Así también lo dejó trascender la ya mencionada denuncia que realizaron los trabajadores del Central Córdoba hacia fines de 1913, quienes al informar que las luces de las señales eran apagadas por la

19 "Un reportaje interesante. Con los compañeros de H. Renancó (FCP).”, $L F$, 1 de diciembre de 1908, 3.

20 "El Central de Buenos Aires. Completo desbarajuste", $L F, 1$ de septiembre de 1909, 3.

21 "El Central de Bs. As. Completo desbarajuste", $L F, 1$ de septiembre de 1909, 3; "El siniestro de Parera. FCER.", LF, 1 de septiembre de 1910, 3; "Los accidentes ferroviarios. En Coronda (FCSF) y Córdoba (C.A.). Muerte del compañero F. Gómez", $L F, 1$ de enero de 1911, 10; "Choque en el FCCBA", $L F$, 1 de marzo de 1911, 9.

22 La Dirección General de Ferrocarriles fue creada en 1888 bajo la dependencia del Ministerio de Obras Públicas. Desde 1909 ejercía un control directo y constante sobre las compañías ferroviarias mediante la realización de inspecciones periódicas en las que, entre otras cosas, se examinaba el material, vías y obras, almacenes, cumplimiento del horario de los trenes y el trato recibido por los usuarios.

23 “El peligro diario", $L F, 1$ de febrero de 1909, 6. 
noche, lo que complicaba y hacía peligrar la circulación de los trenes, advirtieron lo extraño que resultaba que ninguno de los inspectores de la Dirección General -encargados de vigilar el cumplimiento de las disposiciones reglamentarias- hubiera tomado nota de tal violación a la Ley de Ferrocarriles. ${ }^{24}$

Dentro de las medidas que las empresas tomaban en pos de la "economía", y que los trabajadores señalaron como causantes de los accidentes ocurridos en servicio, se encontraban la falta de limpieza de las máquinas, la reducción de personal con un consiguiente recargo de tareas, la transgresión al tiempo de descanso de los trabajadores, las deficiencias en las condiciones de seguridad y comodidad del personal, y la ubicación de trabajadores inexpertos y/o menores de edad en tareas peligrosas. ${ }^{25}$ Este último fue el caso del cambista del Ferrocarril Sud y socio de la FOF, Eusebio Delgado, de 18 años de edad, quien el 5 de abril de 1913 terminó con un dedo totalmente destrozado al realizar un enganche de vagón en la estación La Madrid, en el centro de la provincia de Buenos Aires. Debido a la gravedad de la herida, al día siguiente fue trasladado al Hospital Británico de la localidad, en donde falleció unos días después. Quien escribió la crónica para publicar en el periódico gremial se quejó de los superiores que, "con una inconciencia verdaderamente criminal”, ponían en tareas peligrosas a personas nuevas sin ninguna práctica en el servicio. ${ }^{26}$

Si bien todas las empresas fueron acusadas de hacer economías en perjuicio del personal, el ferrocarril Central Norte, en manos del Estado, fue particularmente denunciado por LF. De manera frecuente, corresponsales de distintas secciones lo acusaron de estar a la cabeza de los ferrocarriles peligrosos, como resultado del "desquicio" técnico y administrativo de sus superiores, y denunciaron el descuido de su material rodante y sus vías, que redundaba en pésimas condiciones de trabajo y frecuentes accidentes. ${ }^{27}$ Hasta

24 "En el Ferrocarril C. Córdoba. Economía mal entendida", $L F, 15$ de octubre de $1913,2$.

25 "La economía mal entendida. Como se practica en el Gran Oeste. Sus consecuencias", $L F, 1$ de mayo de 1908, 2; "Los maquinistas, las máquinas y las empresas”, $L F, 1$ de diciembre de 1908, 3; "Del Gran Oeste Argentino. Irregularidades en la Sección San Luis", $L F, 1$ de enero de 1909, 5; "Choque de trenes. En General Rodríguez. FCO”, $L F, 1$ de abril de 1909, 4; "De Palmira”, $L F, 15$ de julio de 1913, 6; "Abuso de las empresas. Proceder sistemático", EOF, abril de 1914, 2; "Del Central Norte", $L F, 15$ de agosto de 1915, 5.

26 “General La Madrid”, EOF, mayo de 1913, 2.

27 “Abusos en el Central Norte", LF, 1 de enero de 1908, 2; "Del Central Norte. Las irregularidades. Suma y sigue...”, LF, 1 de marzo de 1909, 6; "El desquicio del Central Norte", $L F, 1$ de mayo de 1910, 1; "El Central Norte. Su desquicio", $L F, 1$ de septiembre de 1911, 4; "De General Güemes. Otra víctima del Central Norte”, $L F, 15$ de junio de 1913, 6; "En el F.C. Central Norte. Un hecho 
tal punto llegó el descontento que hacia fines de 1911 una nota publicada en el periódico gremial aseguró que era preferible que la línea pasara a manos de una compañía privada, que por muy mala que fuera sería mejor que la administración estatal. ${ }^{28}$ En septiembre de 1913, LF informó de un grave accidente ocurrido en este ferrocarril y afirmó que en el Central Norte ocurría la proporción más alta de accidentes ferroviarios. Antes de relatar el hecho, aseguró:

Las causas del accidente son bien conocidas; infinidad de veces las hemos expuesto en nuestra Revista y hoy volvemos a repetirlas. Una administración pésima, un afán de economía injustificado y contraproducente y una despreocupación criminal, son los factores que han llevado al Central Norte a ese descrédito público que sobre él pesa y las causales de todos los accidentes ocurridos. ${ }^{29}$

No solo LF se quejaba de esta línea, sino que también la prensa y distintos centros comerciales del interior protestaron por su mal servicio. ${ }^{30}$

Otras de las quejas que tuvieron lugar por estos años estuvo relacionada con ciertas actitudes de las superioridades de las compañías, que eran entendidas por los trabajadores y sus gremios como una muestra más de la falta de interés de las empresas por su personal y su público. Varias noticias denunciaron cómo en casos de accidentes, inclusive algunos con trabajadores fallecidos, los jefes mostraron mayor preocupación por el material rodante que por sus empleados. ${ }^{31}$ En un choque ocurrido en Ingeniero White en mayo de 1913, en el que resultaron heridos cuatro trabajadores, la crónica publicada en $L F$ señaló que la primera preocupación de la superioridad del Sud había sido la de saber si las máquinas habían sufrido perjuicios y cuántas vacas y novillos habían muerto. ${ }^{32}$ Las organizaciones gremiales consideraban que el desinterés por la vida de los trabajadores también se expresaba en la demora de los superiores en enviar trenes de auxilio, llevar los heridos al hospital y trasladar y entregar los cadáveres a sus familiares y compañeros. ${ }^{33} \mathrm{~A}$ fines de

vergonzoso", $L F$, 15 de noviembre de 1914, 2; "Lo que pasa en el Central Norte. Como se trata al personal", $L F, 15$ de abril de 1916, 7 .

28 "El Central Norte", $L F, 1$ de agosto de 1911, 2.

29 "De General Güemes. Grave accidente", $L F, 1$ de septiembre de 1913, 6.

30 "El derrumbe del Central Norte", $L F, 1$ de febrero de 1911, 2.

31 "Terrible choque en el FCO. El compañero Etcheverry gravemente herido", LF, 1 de enero de 1911, 3; "De Güemes. Horrible catástrofe. Muerte del cro J.

Arévalo”, $L F, 1$ de febrero de 1913, 7; “Abuso de las empresas. Proceder sistemático", EOF, abril de 1914, 2.

32 "De Ingeniero White. La verdadera fraternidad", $L F 1$ de junio de 1913, 7.

33 "Una catástrofe más. Nuestras predicciones se cumplen. Las "vías libres" en el C. y R.", $L F, 1$ de agosto de 1909, 1; "Bahía Blanca. Federación Obrera Ferrocarrilera”, EOF, noviembre de 1912, 3; "Horrible desgracia”, EOF, junio de 1913, 4. 
1913, en el "perpetuo aliado de la muerte", como denominaba LF al Central Norte, tuvo lugar un accidente que costó la vida a un guarda y un pasaleña y dejó a otros trabajadores heridos. Luego de narrar las circunstancias en las que se produjo el accidente, al descarrilar y volcar una de las locomotoras con las que viajaba el tren, las crónicas publicadas en $L F$ y EOF denunciaron el descuido y mala atención recibida por parte de la empresa. El primer auxilio demoró más de cuatro horas en llegar al lugar, el médico que vio a los heridos informó que no había elementos para curar y que recién al día siguiente serían atendidos, sin prestar ningún tipo de asistencia, y los heridos fueron trasladados casi 400 kilómetros en un vagón sin comodidades, por lo que recibieron la primera cura veintiséis horas después de sucedido el accidente. ${ }^{34}$

La desidia patronal también fue denunciada en las noticias que señalaban la deficiencia -y en algunos casos, inexistencia- de los servicios médicos de socorros mutuos brindados por las empresas, y que advertían sobre la falta de botiquines y elementos necesarios para practicar las primeras curas a los trabajadores accidentados. ${ }^{35}$ A fines de abril de 1913, un socio de la FOF, cambista de la sección Rosario del Central Argentino, envió una nota al redactor del periódico gremial en la que narró lo sucedido a su colega Antonio Roldán unos días antes, cuando, al encontrarse enganchando unos vagones, quedó apretado dentro de un paragolpes, y resultó con una costilla rota, un brazo dislocado y contusiones internas de gravedad. Tras discutir con la policía, que al llegar al lugar impidió que Roldán fuera levantado y trasladado adonde pudieran efectuarle una primera cura, alegando que primero debían hacer el sumario en el lugar del hecho, los compañeros del accidentado solicitaron la presencia del médico de la empresa. Este se hizo presente recién pasadas veinticuatro horas $\mathrm{y}$, sin revisarlo, preguntó al cambista si estaba enfermo y le firmó una receta. Quien escribía se quejaba de que para ser atendidos de este modo precario estaban obligados a pagar $\$ 1,20$ por mes a la sociedad de socorros mutuos de la compañía. ${ }^{36}$ Este no fue el único caso en que los trabajadores denunciaron a estas sociedades, de las que frecuentemente se quejaban por su mal funcionamiento y demoras en brindar asistencia.

Otro reclamo de los trabajadores estuvo relacionado con los intentos de las empresas por culpabilizar a los trabajadores en los casos de accidentes. A

34 "San Cristóbal. Las calamidades de Ferrocarriles del Estado", EOF, agosto de 1913, 4; "De San Cristóbal", $L F, 1$ de noviembre de 1913, 6

35 "Bahía Blanca. Federación Obrera Ferrocarrilera", EOF, noviembre de 1912, 3; "Rosario", LAO, 7 de diciembre de 1912, 4; "De Güemes. Horrible catástrofe. Muerte del cro J. Arévalo”, $L F, 1$ de febrero de 1913, 7; "De Ingeniero White. La verdadera fraternidad", $L F, 1$ de junio de 1913, 6; "Del Central Norte, $L F$, 15 de agosto de 1915,5 .

36 "Sección Rosario", EOF, mayo de 1913, 3. 
principios de 1910, por ejemplo, una circular emitida por el Central Córdoba fue denunciada en las páginas de $L F$ por avisar que, en vista de los frecuentes descarrilamientos, los cuales según la empresa eran producto del exceso de velocidad, se responsabilizaría a los maquinistas. ${ }^{37}$ Esta compañía no fue la única en culpabilizar a los trabajadores, siendo frecuentes las multas, suspensiones y exoneraciones al personal que había sufrido un accidente y al cual se consideraba responsable del mismo. ${ }^{38} \mathrm{Al}$ igual que en el descarrilamiento que le costó la vida al foguista Colombo, a fines de 1911, tras un accidente producido en las proximidades de la estación Dolores del Ferrocarril Sud, la superioridad de esta empresa afirmó que el incidente había sido consecuencia de la alta velocidad con la que conducía el maquinista de $1^{\circ}$ clase, Santiago Tomás Poole. Pero a diferencia del accidente del Golf, en el cual finalmente se pudo comprobar que el descarrilamiento se había debido a un desperfecto en la vía, en este caso la superioridad fue intransigente con su veredicto y decidió rebajar al maquinista Poole a $3^{\circ}$ clase. ${ }^{39}$

También, fue común que los trabajadores que ocupaban determinados puestos, como los maquinistas y foguistas, fueran detenidos en casos de accidentes, sobre todo cuando había daños a terceros, como sucedía en los arrollamientos de personas. Una de las quejas más reiteradas en las páginas del periódico de LF apuntó a evidenciar la criminalización de los trabajadores accidentados en servicio, muchos de los cuales llegaron a ser condenados a prisión. ${ }^{40}$ Distintas notas a lo largo de los años se encargaron de denunciar los malos tratos recibidos por los trabajadores durante su estadía en las comisarías, y acusaron a las autoridades de las empresas por no intervenir para liberar a su personal. ${ }^{41}$ A la vez que los gremios realizaron gestiones

37 “De Sección Talleres FCC Córdoba”, LF, 1 de marzo de 1910, 7.

38 "Del Central Norte. Continúan los concretos", $L F, 1$ de junio de 1908, 6; "El derrumbe del Central Norte", $L F, 1$ de noviembre de 1910, 5; "Un abuso", EOF, marzo de 1913, 3; "San Agustín", EOF, septiembre de 1913, 3; "Otra injusticia de Greaven. El caso del maquinista Pizzatti”, $L F, 15$ de junio de 1914, 4; "Las tramas de las vías y las de las Empresas", $L F, 15$ de diciembre de 1914, 2.

39 "El accidente de Dolores F.C.S. Lo que opina el personal y lo que dice la empresa", $L F, 1$ de noviembre de 1911, 5. Las clases eran determinadas por cada compañía de acuerdo a la antigüedad del trabajador configurando así el escalafón de ascensos. En general todas las compañías tenían cinco clases de maquinistas y cinco de foguistas.

40 “Asunto Romera", $L F, 1$ de abril de 1908, 2; "Del Argentino del Norte”, $L F, 1$ de noviembre de 1913, 7; "Una condena injusta. La prisión del maquinista Mezzorano. Gestiones de La Fraternidad", $L F$, 1 de junio de 1915, 4. Frente a los fallos que condenaron a maquinistas a prisión, LF intervino para gestionar su indulto, lo que en varias oportunidades logró ("La causa del compañero Romera. Su indulto", $L F, 1$ de mayo de 1908, 1).

41 "En el Noroeste Argentino. Las policías de tierra adentro", $L F, 1$ de marzo de 1908, 5; "En plena cafrería”, $L F, 1$ de abril de 1910, 2; "La prisión por accidentes en servicio. La prisión del compañero Iglesias", $L F$, 15 de agosto de 1912, 3; 
ante las compañías, solicitando una mayor y más rápida intervención de los abogados y procuradores en los casos de trabajadores detenidos, y ante las jefaturas policiales provinciales, para que se tratara al personal "con las consideraciones a que tienen derecho", ${ }^{42}$ denunciaron la desidia de las empresas que no realizaban las gestiones para asistir al personal detenido, que quedaba de este modo abandonado. Frente a esta situación, la ayuda y solidaridad gremial se tornaban de vital importancia. La dirigencia de LF colaboraba con los socios que eran detenidos de distintas maneras, ya fuera enviando comida o brindando el servicio de abogados consultores. ${ }^{43}$

Contra las situaciones que hasta aquí se mencionaron, consideradas injustas, abusivas, arbitrarias, producto de la desidia y afán de lucro de las empresas, los trabajadores y sus gremios protestaron y reclamaron ante estas y los poderes públicos. Las exigencias fueron variadas y abarcaron diversos aspectos que hacían al trabajo, las condiciones laborales y los riesgos y responsabilidades que estas implicaban. De este modo, los trabajadores opusieron sus propias vivencias y demandas ante quienes administraban las empresas y los hombres del Estado. Pero no sólo protestaron en las páginas de los periódicos gremiales. También, en algunos casos, y frente a la ausencia de una legislación que brindara protección en caso de accidentes ocurridos en el trabajo, se presentaron ante la Justicia para iniciar una demanda que resarciera los daños ocasionados.

\section{Las demandas ante la Justicia}

Recurrir a la Justicia no fue la herramienta más extendida entre aquellos trabajadores accidentados pero, aun así, para algunos fue la única posibilidad de obtener un resarcimiento en épocas en las que no existía una ley que protegiera a los obreros frente a un infortunio sucedido en el trabajo. Si bien ante accidentes ocurridos en servicio algunas empresas ferroviarias podían otorgar indemnizaciones u otras compensaciones a sus trabajadores, lo cierto es que estas funcionaban como concesiones graciables, es decir, no estaban sujetas a ninguna norma y dependían de la voluntad de jefes y superiores que

"Las prisiones por accidentes ferroviarios. Libertad de los detenidos del Rosario”, $L F$, 15 de mayo de 1914, 3; "La prisión de los compañeros Fagan y Hardy", $L F$, 1 de julio de 1913, 2; "Los accidentes ferroviarios en Santa Fe. Los casos de los maquinistas Biffi y Peressni”, $L F$, 15 de mayo de 1915, 4; "Una buena actuación", $L F, 15$ de mayo de 1916, 8; "Buscando una solución 'LA FRATERNIDAD’ redita y amplía su capítulo de cargos”, $L F, 15$ de julio de 1917, 2.

42 “Prisión del personal. Nota a los gerentes", $L F, 1$ de agosto de 1908, 2.

43 “Dr. Agustín B. Gambier", LF, 1 de mayo de 1909, 3. 
solían obrar con criterios arbitrarios y discrecionales. ${ }^{44}$ Por este motivo, ante un accidente de trabajo, algunos obreros $-\mathrm{o}$ sus familiares, cuando el incidente resultaba mortal- decidieron iniciar una demanda judicial para reclamar una indemnización que compensara los daños sufridos. ${ }^{45} \mathrm{~A}$ veces la conseguían, aunque nada estaba asegurado de antemano y el fallo variaba según las particularidades de cada caso, las estrategias de los abogados, el juzgado en el que era presentado y el juez que se hiciera cargo de la causa, entre otros factores.

En este apartado se examinan dos demandas judiciales por accidentes laborales iniciadas por trabajadores ferroviarios, o algún familiar, en los años anteriores a la sanción de la ley de accidentes de trabajo de 1915. Al examinar las causas presentadas en la Justicia, este escrito concibe a los tribunales como una arena de disputa, tensiones y negociaciones en la que se redefinieron las obligaciones y responsabilidades de los patrones y los derechos de los obreros, y considera que las demandas, fallos y debates que allí tuvieron lugar abrieron el camino para que la legislación de 1915 fuera posible. A partir del análisis de los fallos publicados en el Boletín del Departamento Nacional del Trabajo se busca rastrear las huellas de las voces de los trabajadores y sus familiares y reconstruir los móviles, expectativas y estrategias puestas en juego para conseguir un resarcimiento. ${ }^{46}$

Los fallos judiciales publicados en los boletines del DNT eran, en general, aquellos que habían cobrado cierta notoriedad para sus funcionarios debido a que sentaban jurisprudencia sobre algún asunto en particular, en este caso

44 Para más información, ver Florencia D’Uva, "Las políticas de beneficios de las empresas ferroviarias desde la perspectiva de los trabajadores. Argentina, primeras dos décadas del siglo XX", Revista Notas Históricas y Geográficas, 24 (2020): 132-167.

45 Aunque iniciar una demanda no garantizaba la obtención de una indemnización, podía ser una estrategia de los damnificados para acelerar el cobro de alguna suma prometida por la empresa u obtener alguna otra compensación no monetaria. En su informe de 1902, Juan Bialet Massé señaló que era frecuente que, para eludir obligaciones judiciales, las empresas ferrocarrileras otorgaran al lesionado alguna colocación y, en cuanto pasara el tiempo de prescripción de la acción, lo despidieran con cualquier pretexto. Otra posibilidad era que le ofrecieran al damnificado una cantidad más o menos irrisoria, y si este se resistía se lo amenazaba con no darle nada y en algunos casos, inclusive, se mandaba a decir a las viudas que, aunque no tenían "derecho a nada", generosamente se les iba a dar pasaje y algo para lutos, y las mujeres -explicaba Massé- "ilusamente” se lo creían. Juan Bialet Massé, Informe sobre el estado de las clases obreras en el interior de la República, Tomo II (Buenos Aires: A. Grau, 1904), 328.

46 Creado en 1907, a través de un elenco de funcionarios y profesionales especializados, el DNT llevó a cabo detallados estudios, estadísticas e inspecciones que tenían como fin conocer y regular la realidad del mundo del trabajo en la Argentina de principios de siglo. 
los accidentes de trabajo. En las sentencias, las declaraciones de los demandantes y demandados aparecen de manera indirecta en los considerandos del juez, lo que limita la información disponible sobre quiénes eran los que iniciaban el litigio, cómo se presentaban a sí mismos y a los hechos, cuáles eran sus pretensiones y sus argumentos. Igualmente, una lectura a contrapelo de los fallos permite advertir qué ponían en juego los trabajadores accidentados para conseguir lo que buscaban y cómo intentaban articular un argumento sólido que demostrara que merecían un resarcimiento. También permite reconstruir parte de la vida de esos trabajadores y sus familias, quienes en un momento de su vida se presentaron ante la Justicia y expresaron quiénes eran, dónde y cómo trabajaban, qué los motivaba a litigar, qué pretendían recibir a raíz de los daños y perjuicios sufridos, entre otras cuestiones. Al hacerlo asumían un rol particular, situándose no solo como trabajadores sino también como sujetos de derechos.

Iniciar una demanda judicial implicaba arriesgar tiempo y dinero, sin tener la certeza de que el resultado iba a ser el esperado. Los demandantes debían desarrollar estrategias que les permitieran argumentar la justicia de su reclamo, demostrando que eran merecedores de una indemnización. Hasta 1915, no existía el reconocimiento del "riesgo profesional" -el riesgo inherente al desempeño del trabajo-, por lo cual el trabajador y su abogado debían demostrar que el accidente era imputable a culpa o negligencia del patrón para el que trabajaba. ${ }^{47}$ Pero ello no era tarea sencilla. Un informe elaborado por el funcionario del DNT Federico Figueroa en junio de 1912, afirmó que en los pocos juicios iniciados hasta 1905 aproximadamente, "el patrono demandado, no solo mostraba que el caso era enteramente ajeno a toda previsión (...) sino que, gracias a la fácil adquisición de testigos, llegaba hasta probar que en el accidente había existido negligencia o culpa del obrero". ${ }^{48}$ Además, exponía que la mayoría de los accidentes eran resultado del "riesgo profesional", es decir, de hechos fortuitos, inevitables, resultado de la misma actividad laboral, en los que no existía culpa o negligencia del patrón ni del obrero. Como consecuencia, Figueroa afirmaba que el trabajador accidentado se veía forzado a resignarse ante el daño sufrido o a recibir una pequeña cantidad de dinero ofrecida por el patrón a título de caridad, con el fin de evitar las molestias de una posible demanda judicial. ${ }^{49}$ De todos modos, advertía, hacia 1905 varios jueces habían comenzado a contemplar la precaria situación de los obreros así como los crecientes peligros del maquinismo, encuadrando implícitamente sus sentencias dentro del principio del riesgo profesional. El argumento se basaba encu el

\footnotetext{
47 "La jurisprudencia nacional sobre accidentes de trabajo", Boletín del Departamento Nacional del Trabajo (en adelante BDNT), 20 (1912): 36.

48 "La jurisprudencia nacional", BDNT, 36.

49 "La jurisprudencia nacional”, BDNT, 36.
} 
reconocimiento de que la explotación industrial implicaba riesgos inevitables y muchas veces imprevisibles, cuyas consecuencias debía soportar el beneficiario..$^{50}$ Dentro de estas sentencias registradas por el DNT, dos corresponden a accidentes de trabajo ocurridos en los ferrocarriles.

El 12 de agosto de 1908, José Alleva, quien trabajaba como cambista en la empresa de capitales franceses Ferrocarril Provincial de Santa $\mathrm{Fe}$, fue trasladado a la estación Josefina, ubicada a 130 kilómetros de la capital de la provincia, para reemplazar al cambista de dicha estación que se encontraba enfermo. Eran la 13.40 de la tarde cuando, luego de dar entrada a un tren de pasajeros procedente de San Francisco, Alleva corrió al lado del tren en marcha para cortar la máquina que debía cambiarse, pero tropezó, cayó, y el penúltimo vagón le destrozó el pie izquierdo. Luego de trasladarlo unos 100 kilómetros hasta la localidad de Pilar, donde se le realizó la primera cura, la superioridad de la empresa lo trasladó al Hospital Italiano de la capital provincial, en donde debieron amputarle el pie, situación que lo imposibilitó para continuar desempeñando su trabajo habitual. ${ }^{51}$ Luego de intentar, sin éxito, obtener una indemnización por parte de la compañía, José decidió llevar el caso a la Justicia e inició una demanda solicitando una indemnización por daños y perjuicios que, consideraba, le correspondía por el derecho establecido en el artículo 156 del Código de Comercio. Según este artículo, en caso de daños o pérdidas extraordinarias acontecidas al factor o dependiente en servicio prestado al principal, este debería cargar con la indemnización del referido daño o pérdida, a juicio de arbitradores. ${ }^{52}$

Frente al pedido del cambista, la compañía argumentó que el accidente había ocurrido por la imprudencia de Alleva, quien había resbalado al pretender subir a uno de los coches del tren en movimiento, maniobra que estaba prohibida por la Ley de Ferrocarriles. Explicó, asimismo, que no se le habían exigido al cambista atenciones mayores a las que le correspondían, ni superiores a las fuerzas ordinarias de un hombre. ${ }^{53}$ Asimismo, solicitó la declaración de dos testigos que habían estado presentes cuando ocurrió el incidente: la señora María L. de Casanova, mujer del cambista a quien Alleva reemplazaba, y el señor Padovani, jefe de la estación Josefina, en donde había tenido lugar el accidente. La mujer declaró que después de dar entrada al tren, Alleva corrió tras este y, cuando lo alcanzó, pretendió subir a uno de los coches del tren en movimiento produciéndose el accidente, a veinte metros de donde estaba ella parada. ${ }^{54} \mathrm{El}$ segundo, curiosamente, declaró que "el

\footnotetext{
50 “La jurisprudencia nacional”, BDNT, 41.

51 "La jurisprudencia argentina en los accidentes del trabajo", BDNT, 17 (1911): 281.

52 "La jurisprudencia argentina”, BDNT, 283-284.

53 "La jurisprudencia argentina", BDNT, 282.

54 "La jurisprudencia argentina”, BDNT, 285.
} 
accidente se produjo en las condiciones que lo expresa la señora de Casanova: que él con sus propios ojos no vio cuando Alleva se cayó pero se lo dijo la señora nombrada". ${ }^{55}$ Un tercer testigo, José Tolosa, conductor del tren, declaró que iba terminando un parte que debía presentar al jefe, aún con el tren en movimiento, cuando escuchó una voz que decía "se ha caído un linguera". Inmediatamente salió y se encontró con el cambista tirado en el piso y herido. ${ }^{56}$ Ante lo expuesto por la empresa y los testigos, Alleva justificó su accionar y explicó que, si había corrido, lo había hecho para cortar la máquina del convoy que debía quedar en Josefina, "obedeciendo á las órdenes expresas" que había recibido al hacerse cargo del puesto, el cual acarreaba peligros que quedaban expuestos en la frecuencia de los accidentes. De hecho, según había declarado el jefe de estación, el tren no podía demorarse por ninguna causa. ${ }^{57}$

Luego de que el juez de Primera Instancia fallara a favor de Alleva, la empresa apeló y un tribunal de Segunda Instancia, compuesto por tres miembros, fue el encargado de rever la sentencia. Finalmente, los tres vocales del tribunal coincidieron en que el citado artículo del Código de Comercio regía las relaciones entre Alleva y la compañía demandada. Dos de ellos consideraron que la pretendida contravención de Alleva a la Ley de Ferrocarriles no estaba justificada. En cambio, defendieron la doctrina del "riesgo profesional" y sostuvieron que la empresa había incurrido en una falta contra tal ley al tener un solo cambista cuando por la actividad de la estación eran necesarios dos y el artículo $11^{\circ}$ establecía que las empresas debían tener el número de empleados que fuese necesario para que el servicio se hiciera con regularidad y $\sin$ tropiezos ni peligros de accidentes. ${ }^{58}$ Como consecuencia, el 31 de octubre de 1910, la sentencia fue confirmada en Segunda Instancia y la compañía fue condenada a indemnizar a José Alleva por el daño sufrido y a pagar las costas del juicio. 59

Poco menos de un año después, la compañía de capitales británicos Ferrocarril Central Argentino fue condenada a pagar una indemnización a la viuda e hijos de un trabajador fallecido a raíz de un accidente ocurrido mientras se encontraba en servicio. Luego de que la empresa apelara el fallo, este fue ratificado por un segundo tribunal. En este caso, había sido la viuda del guarda tren Ángel Sarmiento la que se había presentado ante la Justicia. El accidente había ocurrido el 17 de noviembre de 1904 mientras el guarda, según narró después su esposa, Dolores Gómez de Sarmiento, se encontraba desempeñando una tarea que no le correspondía, ordenado por sus superiores

\footnotetext{
55 "La jurisprudencia argentina”, BDNT, 285.

56 "La jurisprudencia argentina”, BDNT, 285.

57 "La jurisprudencia argentina”, BDNT, 290.

58 "La jurisprudencia argentina”, BDNT, 290.

59 "La jurisprudencia argentina”, BDNT, 291.
} 
debido a la falta de personal. Dolores decidió iniciar una demanda judicial contra la empresa, por sí y a nombre de sus tres hijos menores, Domingo, Patricio y Sara, para obtener una indemnización por los daños y perjuicios sobrevenidos por la muerte de su esposo, que la mujer estimaba en $\$ 20.000 .{ }^{60}$ En la demanda, la viuda atribuía la responsabilidad del hecho a la culpa o negligencia de la empresa que había trasgredido lo dispuesto por el Reglamento General de Ferrocarriles en su artículo $1^{\circ}$, al no tener el número de empleados suficientes para asegurar la regularidad del servicio y evitar los peligros. Debido a esta circunstancia, según exponía la mujer, era frecuente que su esposo se ocupara en funciones que no le correspondían, como la de enganche y desenganche de vagones, que desempeñaba cuando falleció. ${ }^{61}$

A tono con la declaración de la mujer, en la noticia del accidente publicada en el periódico gremial El Ferrocarril, los compañeros de Ángel, quien tenía treinta y siete años consecutivos de servicio, lamentaron su muerte y señalaron que si bien era guarda, "como de costumbre", debía trabajar como cambista. ${ }^{62}$ Por este motivo, la viuda basaba su reclamo en el hecho de que la compañía había incumplido lo establecido por el mencionado artículo del Reglamento General de Ferrocarriles que establecía que

Toda empresa deberá tener en las estaciones, en los trenes y en todo el trayecto del camino, de día y de noche, desde que empiece hasta que termine el movimiento diario, el número de empleados que fuese necesario, para que el servicio se haga con regularidad y sin tropiezos ni peligros de accidentes. ${ }^{63}$

Si bien la empresa reconoció el hecho, alegó que este no había ocurrido en la forma expresada por Dolores y que tampoco había habido contravención a los reglamentos ni omisiones en el servicio de empleados, por lo que no era imputable la responsabilidad que se le atribuía.

En la reunión de pruebas que siguió a la apertura de la causa, dos testigos presenciales confirmaron que no había ningún empleado encargado de avisar que los vagones que habían sido largados iban a juntarse con los vagones parados que el guarda estaba enganchando al furgón, ni tampoco se habían dado los toques de atención reglamentarios, por lo cual Sarmiento no tuvo tiempo de reaccionar y fue aplastado, muriendo prácticamente en el acto. ${ }^{64}$ De las declaraciones de un tercer testigo, empleado del Central Argentino, también se desprendía que en la estación Ballesteros, donde tuvo lugar el

\footnotetext{
60 “Jurisprudencia de nuestros tribunales”, BDNT, 24 (1913): 506.

61 "Jurisprudencia”, BDNT, 507.

62 “Ángel Sarmiento”, El Ferrocarril, 1 de diciembre de 1904, 4.

63 "Ley y Reglamento General de los Ferrocarriles Nacionales" (Buenos Aires:

Ministerio de Obras Públicas, Dirección General de Ferrocarriles, 1911 ), 47.

64 "Jurisprudencia”, BDNT, 508.
} 
incidente, no había trabajadores especialmente ocupados en las tareas de maniobras, por lo cual era normal que los guarda trenes se ocuparan de realizarlas, además de desempeñarse como guardas. ${ }^{65}$ Esta circunstancia era únicamente responsabilidad de la empresa, ya que según lo dispuesto por el artículo $65^{\circ}$ de la Ley de Ferrocarriles,

Es deber de las empresas velar porque todos sus empleados sean diligentes e idóneos. Su responsabilidad hacia los pasajeros y cargadores por daños resultantes de faltas de sus empleados, se extiende a todos los actos ejecutados por éstos en el desempeño de sus funciones. En casos de accidentes, incumbe a las empresas probar que el daño resulta de caso fortuito o de fuerza mayor. ${ }^{66}$

$\mathrm{El}$ artículo $83^{\circ}$ ampliaba: "Si el causante del accidente fuera empleado de la empresa, ésta responderá por los daños y perjuicios causados". ${ }^{67}$

Según se había logrado demostrar, no sólo había habido negligencia por parte de los empleados de la compañía -que no habían observado las precauciones del caso, ni establecido la vigilancia necesaria para prevenir la aproximación de los vagones, ni dado las señales reglamentarias con que debía iniciarse cualquier movimiento de la máquina-, sino que también había habido omisiones de la empresa que contrariaban disposiciones terminantes de la ley y su reglamentación. En base a la comprobación de la denuncia de la viuda, que acusaba a la empresa de haber trasgredido los artículos de la Ley General de Ferrocarriles, el 11 de julio de 1911 el juez condenó al Central Argentino a pagar a la esposa e hijos del guarda Ángel Sarmiento una suma de \$10.000, estipulada en base a la edad de la víctima y al sueldo que percibía como guarda. ${ }^{68}$ En mayo de 1912, la Cámara de Apelaciones confirmó el fallo y resolvió que la responsabilidad de la empresa emanaba no solo de los artículos ya citados de la Ley y Reglamento General de Ferrocarriles sino también de los artículos 902, 1109 y 1113 del Código Civil. ${ }^{69}$ Es interesante analizar esto último a la luz de lo que señaló Bialet Massé en su informe de 1902, al afirmar que si bien el Dr. Vélez Sársfield no había escrito literalmente las palabras "accidente de trabajo", era el Código Civil el que legislaba los accidentes laborales como ningún otro código, ley o reglamento.70

A partir de estos fallos es posible rastrear algunas de las estrategias que los demandantes pusieron en práctica para reclamar lo que consideraban un derecho, así como conocer qué nociones sobre lo justo aparecen implicadas

\footnotetext{
65 “Jurisprudencia”, BDNT, 508.

66 “Ley y Reglamento General”, 24.

67 "Ley y Reglamento General”, 36.

68 “Jurisprudencia”, BDNT, 509.

69 "Jurisprudencia”, BDNT, 510.

70 Bialet Massé, Informe sobre el estado, 307.
} 
en ellas. Con respecto a las primeras, en ambos juicios los trabajadores buscaron demostrar la culpa o negligencia de las empresas, al apelar al Código Comercial, específicamente al artículo 156, así como a la Ley General de Ferrocarriles Nacionales, que regulaba y establecía las condiciones en que debía desempeñarse la actividad de los ferrocarriles. A su vez, quienes iniciaron las demandas eligieron remarcar ciertos hechos o circunstancias que consideraban que podían influir en la decisión final de los magistrados, tales como la gravedad del daño sufrido, que impedía volver a realizar ciertas tareas, o el haber recibido órdenes para realizar la acción que había desencadenado el accidente, la cual, en algunos casos, podía no corresponder con las tareas para las que el trabajador había sido contratado. En relación a las nociones sobre lo justo, aparecen implícitas en las demandas, en las que los trabajadores buscaron demostrar la validez de su reclamo apelando a códigos y leyes que los amparaban. Desde que decidían iniciar una acción en la Justicia, quedaba claro que para los demandantes era esperable que existieran mínimas condiciones de seguridad en los lugares de trabajo, de las cuales las empresas se hicieran cargo, y que estas se ocuparan de resarcir los daños y perjuicios ocasionados en caso de accidentes. Tener en cuenta las acciones emprendidas por los trabajadores y sus familiares en el ámbito judicial permite entender la agencia que tuvieron los propios obreros en la gestación y reconocimiento de sus derechos. Los trabajadores usaron las leyes y reglamentos disponibles para legitimar demandas que tenían una larga historia, así como para redefinir los propios términos de su empleo.

\section{Rupturas y continuidades a partir de la ley}

Luego de arduos y largos debates, y transcurrida más de una década del primer proyecto de ley presentado en el Congreso, en octubre de 1915 se sancionó en Argentina la Ley 9.688 de Accidentes del Trabajo. Si bien tanto la dirigencia de LF como de la FOF habían manifestado en diversos momentos la necesidad de que se legislara en la materia, ${ }^{71}$ fue la primera la que dedicó más atención a seguir el curso de los proyectos que se presentaban, así como a apoyar distintas iniciativas para lograr una legislación. Cuando esta se sancionó, el periódico de LF publicó el texto completo para que "todo el compañerismo se entere de la ley, a la que pueden recurrir" e incitó a los trabajadores a estudiarla y a aportar sus observaciones para su mejor cumplimiento..$^{72}$ Por su parte, los dirigentes de la FOF no se pronunciaron, al menos en su organismo de prensa, y la ley de accidentes pasó desapercibida al lado de la ley de jubilaciones y pensiones ferroviarias que había sido

71 “Objeto y fines”, $L F, 1$ de enero de 1909, 9; “Contra la jubilación”, $E O F$, noviembre de 1913, 1.

72 "La Ley de Accidentes del trabajo", LF, 15 de diciembre de 1915, 1. 
sancionada un mes antes, y a la que el periódico gremial dedicó varias páginas, expresando su descontento y diferencias. ${ }^{73}$ Unos meses más tarde, en mayo de 1916, una nota en EOF expuso de manera más clara la postura del gremio respecto a las leyes en general: "Nunca hemos tenido mucha fe en las leyes. Los representantes de la llamada justicia y legalidad nos inspiraron siempre una saludable desconfianza". ${ }^{74}$ Pero ¿qué sucedió con los accidentes de trabajo una vez sancionada la ley? ¿Hubo cambios significativos para los trabajadores que sufrían un accidente? ¿Cómo se pusieron en práctica las disposiciones de la ley?

El principal cambio estipulado a partir de la sanción de la ley consistió en suplantar la teoría de culpabilidad del patrón por la del riesgo profesional. Es decir, mientras que antes de la ley, el obrero accidentado debía probar la culpabilidad del patrón, luego de su sanción tenía derecho a la indemnización, salvo que el accidente hubiera sido motivado por alguna falta grave o voluntad intencional del afectado o por fuerza mayor extraña al trabajo. ${ }^{75}$ Además de esta restricción existían dos limitaciones fundamentales que imponía la ley en su artículo $2^{\circ}$, una referente a la cuantía del salario -al establecer que podrían gozar de los beneficios de la ley los obreros o empleados cuyo salario anual no fuera superior a los $\$ 3.000-$ y otra relativa a la naturaleza de las industrias en las que los trabajadores prestaban sus servicios. Al respecto, en una nota de comienzos de 1916, el periódico socialista La Vanguardia criticó estas limitaciones y afirmó que la restricción salarial era absurda e injusta y que eran pocas las legislaciones extranjeras sobre accidentes de trabajo que determinaban un monto anual de salario como limitativo del derecho a la indemnización. ${ }^{76}$

A mediados de 1916, pasados cinco meses de la reglamentación de la ley, el diario radical La Época decidió realizar una encuesta para saber de qué forma se estaba cumpliendo en la práctica. Según las declaraciones del inspector general del DNT, todavía era imposible tener una idea firme sobre sus resultados, aunque "todo hace pensar que la ley va resultando buena" y de

73 "Frente a la ley", $E O F$, octubre de 1915, 2; "La jubilación", $E O F$, diciembre de $1915,1$.

74. "Legalidad burguesa", $E O F$, mayo de 1916, 3. En el tratamiento de la ley que hicieron los gremios ferroviarios se pueden apreciar las distintas posturas que mantenía cada uno frente al rol del Parlamento y del Estado para mejorar las condiciones de la vida obrera. Seguramente, ello estaba ligado a las distintas corrientes ideológicas y políticas que tenían presencia en los distintos sindicatos, siendo el socialismo mayoritario entre los dirigentes de LF y el sindicalismo revolucionario el que mantenía estrechos vínculos con la cúpula de la FOF, la cual adhería a la FORA IX, de orientación sindicalista.

75 "La Ley de Accidentes del trabajo", LF, 15 de diciembre de 1915, 2.

76 "Accidentes del trabajo. Limitaciones al derecho del obrero", La Vanguardia, 1 de enero de 1916,5 . 
"alto e inmediato beneficio para los trabajadores". ${ }^{77}$ A continuación, la nota enumeraba algunas de sus ventajas e inconvenientes, y la forma de subsanarlos. Sobre las primeras, señaló que las indemnizaciones fijadas por la ley eran superiores a las que regían con anterioridad en los seguros espontáneos con que contaban algunos trabajadores, sobre todo en la Capital Federal, y que, a partir de la ley, el concepto de "accidente de trabajo" se ampliaba enormemente, al acabar con las condiciones de las pólizas que en muchos casos invalidaban el derecho del obrero. También, según se informó, gracias a la ley, producido un accidente, "sabe el obrero inmediatamente qué es lo que le corresponde percibir" y, en caso de no recibir la cantidad debida, el DNT le brindaba patrocinio para obtenerla. ${ }^{78}$ En relación a los inconvenientes, informó que el principal emanaba de la obligación consignada en la ley de efectuar el depósito de la indemnización en la Caja de Pensiones y Jubilaciones, para que con esa suma se compraran títulos de la deuda pública nacional y se diera la renta a los herederos del muerto. De este modo, advirtió La Época, los herederos, en vez de recibir la suma de dinero que representaba el total de la indemnización, cobraban por mes una cantidad "insignificante" que no llegaba a representar auxilio alguno. Además, con este sistema, las empresas o patrones desembolsaban una suma menor al monto total de la indemnización, que, al ser invertida por la Caja, iba generando intereses que con el tiempo completaban la suma correspondiente al resarcimiento. El inspector del DNT consultado por el periódico explicó que, advertido este problema, se estaban realizando gestiones para proponer un nuevo proyecto de ley que cambiara el sistema de cobro por uno más beneficioso para los obreros y sus familiares. ${ }^{79}$

Transcurrido un año y medio de la sanción de la ley, funcionarios del DNT se dispusieron a recopilar información sobre los resultados que hasta el momento se habían obtenido, con el propósito de incorporar algunas modificaciones que ampliaran los beneficios que se otorgaban a los trabajadores accidentados. ${ }^{80}$ Entre las cuestiones que se estaban contemplando se encontraba la del destino de los depósitos de las cantidades a indemnizarse, la conveniencia o no de la extensión del seguro, y la ampliación de las categorías ocupacionales comprendidas en la ley. Por entonces, una nota publicada en el periódico de la FOF llamó la atención sobre cómo la "deficiente ley" sancionada en el Congreso era violada "descaradamente", lo que afectaba especialmente al gremio ferroviario, que era uno de los más expuestos a perder la vida, con accidentes que se producían

77 "Experimentación de la ley de accidentes de trabajo. Una encuesta al respecto",

La Época 8 de junio de 1916, 5.

78 “Experimentación de la ley”, La Época, 5.

79 "Experimentación de la ley", La Época, 5.

80 "Reformas a la ley de accidentes", La Época, 26 de mayo de 1917, 4. 
con una frecuencia alarmante. ${ }^{81}$ Además de criticar las condiciones laborales -como los recargos de trabajo y la reducción de personal- que acrecentaban los peligros a los que se exponía a los trabajadores, señalaba que las empresas siempre buscaban librarse de las indemnizaciones impuestas por la ley, al intentar demostrar que el accidente se había debido exclusivamente a culpa grave de la víctima. Denunciaba específicamente al Ferrocarril Pacífico que, en una circular dirigida a los jefes, había recomendado que al levantarse el acta de cada accidente, se intentara hacerla firmar por algunas personas ajenas al personal, para que tuviera mayor valor legal a la hora de probar que el incidente se había debido exclusivamente a una falta obrera. ${ }^{82}$ Por este motivo, la nota advertía a los socios que, según lo dispuesto por la ley, los accidentes de trabajo debían ser denunciados por la víctima, o algún familiar, ante la comisaría o juzgado de paz, así como al DNT, a la mayor brevedad posible. Si se dejaba transcurrir más de treinta días, señalaba, el obrero sufriría un $25 \%$ de descuento en su indemnización. A continuación, explicaba cuáles eran las obligaciones de las empresas en casos de fallecimientos y de accidentes que requirieran más de seis días de asistencia y advertía que la declaración de testigos era muy importante, por lo que era conveniente que los trabajadores se prestaran voluntariamente. También aclaraba que, si bien las empresas estaban exentas de responsabilidad en casos en que el accidente se hubiera debido a una infracción del obrero, si esta hubiera sido cometida obedeciendo a órdenes de la superioridad, entonces la empresa era responsable. ${ }^{83}$ Dadas las instrucciones y explicaciones que se impartían, es factible pensar que muchos ferroviarios no conocían o comprendían los derechos que les correspondían según la legislación. La nota finalizaba afirmando que, debido a que varias disposiciones de la ley perjudicaban los derechos del personal, la cooperación obrera era fundamental para "hacer cumplir las pocas disposiciones que nos favorecen". ${ }^{84}$

Por su parte, hacia mediados de 1918, dirigentes de LF señalaron que la ley, si bien para los deudos era "una ilusión de algo", era "incompleta y deficiente" y daba "bien poco" a los hogares ferroviarios, que seguían dependiendo, en buena medida, de los socorros que brindaba el gremio en casos de accidentes. Por este motivo, era indispensable reforzar la obra societaria para exigir de los poderes públicos, y "ley en mano", lo que les correspondiera y de este modo allegar un verdadero consuelo a los hogares en desgracia. ${ }^{85}$ Por

81 "Los accidentes de trabajo", EOF, abril de 1917, 3.

82 "Los accidentes de trabajo", EOF, 3. Sobre cómo los patrones se aprovecharon de las deficiencias y contradicciones que presentaba el tex to de la ley para eludir su responsabilidad, ver: María Ester Rapalo, Patrones y obreros. La ofensiva de la clase propietaria, 1918-1930 (Buenos Aires: Siglo XXI, 2012), 209-219.

83 "Los accidentes de trabajo", EOF, 3.

84 "Los accidentes de trabajo", EOF, 3.

85 "Los que se van", $L F, 15$ de abril al 31 de mayo de 1918, 15. 
entonces, por medio de un decreto del Poder Ejecutivo, se aprobó una reforma a la ley de accidentes referente a la forma de pago de la renta correspondiente a las familias de los obreros muertos. El objetivo era modificar el sistema de pago que dejaba en una crítica situación económica a los derechohabientes de los obreros muertos en accidentes, debido a la insuficiencia de las rentas que se les entregaba, lo que en muchos casos llevaba a los herederos a optar por un juicio ordinario y renunciar así a los beneficios de la ley que había sido dictada, en teoría, para favorecerlos. ${ }^{86}$ Sin embargo, dicha modificación no llegó a satisfacer los reclamos de los ferroviarios de LF y, unos meses más tarde, el periódico del gremio informó que entre los asociados se había llevado a cabo una junta de firmas para obtener una legislación "justa y práctica" y que se había presentado el petitorio ante la Cámara de Diputados para solicitar el "pronto despacho" de las modificaciones proyectadas a la ley, las cuales estaban siendo estudiadas. ${ }^{87}$

Un año más tarde, en septiembre de 1919, todavía no había novedades respecto a las modificaciones. Mientras tanto, el socio de LF Luis Caso, perteneciente a la sección Lynch del Ferrocarril Central de Buenos Aires ubicada en las afueras de la Capital Federal, publicó un "Manual del Ferroviario" que tenía como fin explicar demostrativamente la Ley de Jubilaciones Ferroviarias y la de Accidentes de Trabajo, presentando ejemplos prácticos sobre la forma de hacer los trámites para obtener sus beneficios. ${ }^{8}{ }^{8}$ Según afirmó el periódico gremial, el volumen sería de suma utilidad a todos los ferroviarios que necesitaran gestionar los beneficios de la ley ya que contenía indicaciones y otros datos útiles. En palabras del autor,

el articulado de la ley, como el articulado de todas las leyes, resulta de difícil comprensión para aquellos que el afán de toda su vida no ha sido otro que el de trabajar (...) Para ellos son las aclaraciones que este folleto contiene, rogando a mis buenos lectores toleren la deficiente redacción o el exceso de detalles un tanto extensos que su texto pudiera tener, pues ante todo he tratado de darle la mayor claridad posible, con el fin de que los lectores puedan fácilmente establecer cuando se hallen comprendidos dentro de las condiciones exigidas por la Ley. ${ }^{89}$

Nuevamente, a partir de estas noticias, es posible imaginar lo complejo que podía ser para un trabajador ferroviario -inclusive para aquellos que tenían gran calificación y estaban alfabetizados, como era el caso de los maquinistas y foguistas- comprender los alcances de sus derechos e iniciar un trámite para que se le concedieran los beneficios de la legislación.

\footnotetext{
86 "La ley de accidentes del trabajo. Nueva reglamentación”, La Época, 26 de junio de $1918,2$.

87 “Accidentes del Trabajo”, $L F, 31$ de agosto de 1918, p. 6.

88 "Manual del Ferroviario", $L F, 15$ de septiembre de 1919, 8.

89 "Manual del ferroviario", $L F, 15$ de octubre y 1 de noviembre de 1919, 4.
} 
Esta no sería la única iniciativa surgida en el seno de LF para explicar cómo proceder en caso de hallarse comprendido dentro de las condiciones exigidas por la ley para acceder a un derecho. Al comenzar 1920 se publicaron distintas noticias en el periódico fraternal que, en vistas del "profundo desconocimiento" que imperaba en el gremio y que redundaba en consultas diarias dirigidas a la Comisión Directiva, buscaban revelar con detalle la escala jubilatoria para los distintos casos de jubilaciones, pensiones y retiros según el sueldo mensual, así como explicar en forma "clara y concisa" el paso a paso de cómo se tramitaba un expediente. ${ }^{90}$ Asimismo, en 1920 y 1921 el periódico gremial publicó información remitida por el centro de estudiantes de la Facultad de Derecho que anunciaba cursos gratuitos de extensión universitaria especialmente dirigidos a los trabajadores para que estos comprendieran los alcances de distintas leyes. ${ }^{91}$ Por su parte, en abril de 1921 un aviso publicado en EOF comunicó que aquellos socios que quisieran solicitar información de orden jurídico sobre asuntos relacionados con la ley de jubilaciones o accidentes del trabajo, podrían asesorarse en la secretaría gremial de forma gratuita y evitar así ser víctimas de estafas de abogados y procuradores "sin conciencia". En caso de ser realmente necesaria la intervención de un profesional, aclaraba, la secretaría podría recomendar letrados honestos y de confianza. ${ }^{92}$

Sin dudas, la ley implicó avances concretos que se tradujeron en mejoras para los obreros, quienes a partir de ella ya no debían demostrar que el accidente se había debido a la culpa o falta de la patronal, pero presentó importantes limitaciones que excluyeron a buena parte de los trabajadores de sus beneficios. Entre ellas, se restringía su alcance a ciertas labores, fundamentalmente industriales, y se establecía un tope a la cuantía del salario, excluyendo de la ley a los obreros o empleados que percibieran más de $\$ 3.000$ anuales. Inclusive aquellos trabajadores a los que la ley sí les reconocía su derecho a percibir una indemnización, en algunos casos debieron enfrentar dificultades para cobrar los pagos. ${ }^{93} \mathrm{Al}$ respecto, la memoria de la sección "Accidentes del Trabajo" de la Caja Nacional de Pensiones y Jubilaciones correspondiente al año 1916, advirtió que las empresas ferroviarias "cuya

90 “Tabla con la aplicación de la escala jubilatoria según la ley 10.650”, $L F, 15$ de diciembre de 1919 y 1 de enero de 1920, 6; "Una visita a la Caja de Jubilaciones y Pensiones. Cómo se tramita un expediente”, $L F, 15$ de febrero y 1 de marzo de $1920,5$.

91 "Centro de estudiantes de derecho", $L F, 5$ de septiembre de 1920, 3; "Cursos de extensión universitaria”, $L F, 5$ de julio de 1921, 12 .

92 “Consultas jurídicas”, EOF, 1 de abril de 1921, 2.

93 "Departamento nacional del trabajo", La Vanguardia 1 de agosto de 1916, 4; "Departamento nacional del trabajo. Infracciones a las leyes obreras", La Vanguardia 3 de agosto de 1916, 1. Uno de estos casos era el de la viuda de Aníbal Rodríguez, maquinista del Ferrocarril Central Córdoba, fallecido a causa de un síncope cardíaco que su esposa atribuía al trabajo. 
obligación de someterse a todas las disposiciones de la Ley 9.688 está fuera de discusión", se mostraban reacias no sólo a depositar las indemnizaciones sino a denunciar los accidentes sufridos por sus trabajadores. ${ }^{94}$ También, entre los trabajadores ferroviarios de distintas compañías sucedió que, mientras que antes de la ley se les abonaba sueldo entero en caso de lastimarse en servicio y quedar imposibilitados para trabajar durante quince días o un mes, luego de la ley las empresas comenzaron a abonar tan sólo medio sueldo, tal como estaba dispuesto en el texto de la legislación. ${ }^{95}$ Como evidencian estas situaciones, la sanción de ley no implicó la conquista indefectible de mayores beneficios y, al menos durante los años iniciales de su implementación, concitó críticas y reclamos de distintos gremios y trabajadores que, al encontrar que la legislación no satisfacía sus aspiraciones, demandaron distintas modificaciones.

\section{Palabras finales}

Este artículo abordó el problema de los accidentes laborales "desde abajo", a partir de la óptica de los propios trabajadores de los ferrocarriles. Su objetivo fue conocer qué conceptualizaciones, expectativas e intereses sobre los accidentes de trabajo, el riesgo profesional y los derechos obreros fueron articulados por los ferroviarios en sus experiencias laborales y sindicales. A partir del análisis de la prensa gremial, pudo reconstruir las principales denuncias y quejas que se gestaron en torno al tema y algunas de las demandas y exigencias que los gremios formularon ante las autoridades de las empresas y los poderes públicos. Considerar algunas demandas judiciales iniciadas por trabajadores accidentados, o sus familiares, para obtener una indemnización durante los años previos a la existencia de una ley, permitió a su vez reflexionar sobre sus propias nociones sobre lo justo y apreciar cómo, en los tribunales, los trabajadores fueron agentes en la gestación y reconocimiento de sus derechos, sirviéndose de las brechas de las leyes vigentes para reivindicar mejores condiciones laborales. Por último, al examinar las implicancias de la ley de accidentes de trabajo de 1915, los cambios y continuidades posteriores a su sanción, se pudieron reconocer ciertos aspectos de la recepción obrera y gremial de la ley y registrar algunas de las quejas y críticas que tanto los trabajadores en general, como los ferroviarios en particular, elaboraron al respecto.

\footnotetext{
94 "La Caja de Accidentes del Trabajo en 1916”, BDNT 36 (1918), 192.

95 "Escalafón de sueldos para el personal de conducción de locomotoras. Versión taquigráfica de las reuniones entre los representantes de los FF.CC. y de 'La Fraternidad' celebradas en el Ministerio de Obras Públicas” (Buenos Aires, 1920), 64 .
} 
Prestar atención a los peligros de la profesión ferroviaria permitió ver otra faceta del trabajo y la conflictividad obrera en los ferrocarriles que, a pesar de haber sido una dimensión constitutiva y característica de este mundo laboral, no ha recibido demasiada atención por las historias dedicadas a examinar las luchas, condiciones de vida y experiencias laborales de los trabajadores ferroviarios. En este artículo se buscó demostrar que la continua exposición a sufrir un accidente influyó en la manera en que los trabajadores ferroviarios entendieron su labor, articularon demandas específicas que apuntaban a reducir los riesgos e incertidumbres que implicaba el trabajo en los rieles y participaron activamente de la conquista de derechos y leyes obreras. 
Title: Railway Workers and Occupational Accidents. Complaints, Claims and Lawsuits in Early Twentieth-Century Argentina

Abstract: Drawing upon union sources, political and commercial newspapers, court rulings, and reports of the National Department of Labor, this article analyzes occupational accidents in Argentine railroads during the first two decades of the twentieth century. It focuses on the complaints and demands made by the workers, their families, and their union organizations, to assess how they experienced the dangers and responsibilities to which they were exposed and what actions they undertook to demand what they considered fair. The aim is to understand the role that workers themselves played in the conquest of better working conditions, rights, and labor laws.

Keywords: railways, accidents, workers, lawsuits, Argentina

Titulo: Trabalhadores ferroviários em face de acidentes de trabalho. Reclamações, queixas e ações judiciais na Argentina no início do século XX

Resumo: Com base em fontes sindicais, jornais políticos e comerciais, decisões judiciais e relatórios do Departamento Nacional do Trabalho, este artigo analisa os acidentes de trabalho nas ferrovias argentinas durante as duas primeiras décadas do século XX. Ele se concentra nas queixas e demandas feitas pelos trabalhadores, suas famílias e suas organizações sindicais, para avaliar como eles vivenciaram os perigos e responsabilidades aos quais foram expostos e que ações empreenderam para exigir o que consideravam justo. O objetivo é compreender o papel que os próprios trabalhadores desempenharam na conquista de melhores condições de trabalho, direitos e leis trabalhistas.

Palavras-chave: ferrovias, acidentes, trabalhadores, demandas, Argentina 